\title{
AO VENCIDO, ÓDIO OU COMPAIXÃO: A PERMANÊNCIA DA PREOCUPAÇÃO SOCIAL NA LITERATURA BRASILEIRA
}

\author{
Marcelo Spalding
}

\begin{abstract}
RESUMO: O presente artigo procura aproximar as personagens D. Plácida, de Memórias Póstumas de Brás Cubas, $D$. Vitória, de Angústia, e Domingas, de Dois Irmãos, das análises sociológicas da literatura de Roberto Schwarz, demonstrando como a presença destas personagens nas narrativas e a influência delas no narrador e no narrado apontam para uma permanência da preocupação social na literatura brasileira.
\end{abstract}

PALAVRAS-CHAVE: Memórias Póstumas de Brás Cubas - Roberto Schwarz-preocupação social

RESUMEN: El presente artículo aproxima las personajens D. Plácida, de Memórias Póstumas de Brás Cubas, D. Vitória, de Angústia, y Domingas, de Dois Irmãos, de las análisis sociologicas de la literatura de Roberto Schwarz, demostrando como la presencia de esas personajens em las narrativas y la influencia de ellas en el narrador y en el narrado indicam para una permanencia de la preocupación social en la literatura brasileña.

PALABRAS-CLAVE: Memórias Póstumas de Brás Cubas - Roberto Schwarz - preocupación social



No capítulo setenta e quatro de Memórias Póstumas de Brás Cubas, D. Plácida conta sua história e menciona uma filha, fruto do seu primeiro casamento, ainda na adolescência. A menina teria quatorze anos, era fraquinha e não fazia nada a não ser namorar os canastrões que lhe apareciam - o que obrigava a mãe a redobrar os cuidados e levá-la consigo nas entregas de costuras - quando fugiu. Fugiu deixando Dona Plácida sozinha e triste, tão triste que pensou em morrer. Mas não morreu, e conheceu a família de Virgília, o que mais tarde lhe valeria figurar na história de Brás Cubas. Entretanto, a filha nunca mais encontrou. Nem o narrador mencionou-a em seus mais de oitenta capítulos seguintes.

Agora permita-nos propor que esta personagem criada e abandonada por Machado de Assis, a filha de D. Plácida, tenha se mudado para Maceió fugindo da mãe com um dos seus canastrões - que naturalmente a deixou - e se tornado empregada doméstica de Luís da Silva, um obscuro funcionário público. Mais ainda: que antes de

\footnotetext{
Mestrando em Literatura Brasileira da Universidade Federal do Rio Grande do Sul, marcelo@marcelospalding.com
} 
morar com o angustiado Silva, a moça, chamada Vitória, tenha gerado uma filha e dado este bebê para uma tribo amazônica de onde freiras a recolheriam ainda criança e a dariam o cristão nome de Domingas.

Claro que D. Plácida, de Memórias Póstumas de Brás Cubas (1881), de Machado de Assis, D. Vitória, de Angústia (1936), de Graciliano Ramos, e Domingas, de Dois Irmãos (2000), de Milton Hatoum, não pertencem à mesma genealogia, mas poderíamos dizer que são avó, mãe e filha de uma família com a mesma sina: servir a seus patrões incondicionalmente para não cair na mendicância num mundo em que sua utilidade é relativa.

O objetivo deste ensaio é aproximar estas três personagens em particular - e a representação da pobreza em geral - em três obras canonizadas e de fases distintas da literatura brasileira para demonstrar como a preocupação social é uma constante no nosso romance mesmo quando não está no ponto central da trama.

Comecemos com D. Plácida, talvez a primeira e de certo a mais estudada empregada doméstica de nossa literatura. Em 1983, Roberto Schwarz já dedicara a ela um capítulo em antologia organizada por ele mesmo, Os pobres na literatura brasileira. Este capítulo de poucas páginas transformou-se numa parte importante do seu livro Um mestre na periferia do capitalismo, em que estuda as Memórias Póstumas com um recorte de classe e dedica aos pobres uma parte inteira e à empregada um capítulo especial, apresentando-a como exemplo do trabalho sem mérito e "um dos momentos mais altos e duros da literatura brasileira" (SCHWARZ, 1997, p. 106).

D. Plácida surge na narrativa de Brás Cubas no capítulo sessenta e sete, quando ele conta da decisão de ter uma casinha para os encontros fortuitos com sua amada e comprometida Virgília. Apresenta a mulher como antiga costureira e agregada da casa de Virgília, a quem guardava grande admiração. Contava Cubas que a mulher não fosse se importar com o vil papel de alcoviteira a que era submetida, mas no capítulo setenta, titulado "D. Plácida", a mulher mostra-se por um lado verdadeira dona de casa, e por outro fareja a intenção dos patrões e dói-lhe o ofício. Cubas conta que custou-lhe muito aceitar a casa, mas afinal cedeu, deixando a entender que um pecúlio feito por ele em nome da velha, no valor de cinco contos, tenha sido necessário e suficiente para acabarlhe com o nojo. A senhora aparecerá novamente no capítulo setenta e três, já integrada à rotina do casal, e no seguinte Brás Cubas interromperá os episódios sobre seu caso com Virgília para contar a história de D. Plácida. É então que o leitor fica sabendo da sua rotina intensa de trabalho desde menina, passando pela adolescência, pela criação da filha e os cuidados com a mãe até o dia em que a filha a abandona e ela conhece a família da Virgília: "estive lá muitos meses, um ano, mais de um ano, agregada, costurando. Saí quando Iaiá casou. Depois vivi como Deus foi servido. Olhe os meus dedos, olhe estas mãos..." (ASSIS, 1997, p. 131).

Roberto Schwarz (2000), no já referido capítulo de Um mestre na periferia do capitalismo, demonstra como coube a D. Plácida colher o pior dos mundos capitalista e escravista, pois ao mesmo tempo que este trabalho concreto sem objetivo além do salário pertence ao universo do capitalismo, a nenhuma estima pelo esforço é do universo escravista, estando ausentes tanto a dignificação burguesa do trabalho quanto o ócio que o escravismo pode proporcionar aos não-escravos. Desta forma, "seus esforços, cuja paga material é incerta e mínima, ficam sem compensação também no plano moral, o que talvez seja a explicação da singular tristeza da personagem” (ibid., p. 107). 
Mais do que identificar D. Plácida como um tipo capital do realismo brasileiro, Schwarz chama a atenção para sua generalidade de classe e sua correspondência com a estrutura social do país. Neste ponto parece válido retomarmos a divisão social proposta pelo crítico ainda em Ao vencedor, as batatas, de 1977.

A chave [da vida ideológica] era diversa. Para descrevê-la é preciso retomar o país como um todo. Esquematizando, pode-se dizer que a colonização produziu, com base no monopólio da terra, três classes de população: o latifundiário, o escravo e o "homem livre", na verdade dependente. Entre os primeiros dois a relação é clara, é a multidão dos terceiros que nos interessa. Nem proprietários nem proletários, seu acesso à vida social e a seus bens depende materialmente do favor, indireto ou direto, de um grande. O agregado é sua caricatura. (SCHWARZ, 1977, p. 16)

Como símbolo dessa multidão dos terceiros, D. Plácida poderia até mesmo tornar-se uma senhora da sociedade se realizasse um bom casamento; não o conseguindo, passou a depender do favor - primeiro da família de Virgília, depois de Brás Cubas - para não cair na mendicância, como confessa temer em dado momento da narrativa: "Eu tinha um medo de acabar na rua, pedindo esmola... Ao soltar a última frase, D. Plácida teve um calafrio" (ASSIS, 1997, p. 132).

Em suma, D. Plácida é, no plano narrativo, uma adjuvante dependente dos caprichos do protagonista a quem serve mesmo que isso custe sua honra, e no plano social um tipo brasileiro próprio do contexto em que o trabalho não é valorizado e o favor torna-se a única forma de subsistência possível para a multidão dos homens livres não-proprietários. É a pobreza transformada em carne e osso, medos e sonhos, manias e desejos.

Também D. Vitória, empregada do protagonista Luís da Silva em Angústia, é uma espécie de síntese desse Brasil pré-industrial em que ainda inexiste a valorização burguesa do trabalho e persiste a lógica do favor como alternativa para a multidão dos homens livres não-proprietários. Como D. Plácida, ela mora na casa do patrão - patrão este que é narrador e protagonista da história -, não tem família, trabalhou a vida toda e teme profundamente a miséria. Note-se que o romance de Graciliano Ramos se passa num contexto histórico bastante diverso do de Machado, o Brasil varguista dos anos 30, distante do período escravocrata. Mas a semelhança de papéis sociais entre as personagens se justifica porque o cenário não é mais a metrópole, e sim a distante Maceió, deslocada das grandes evoluções industriais e em processo tardio de urbanização. Sobre este aspecto o crítico Fernando Cerisara Gil (1999) chega a chamar Angústia de "romance da urbanização", alertando para o fato deste tipo de romance não ser produzido e ambientado no eixo econômico, político e cultural dominante do país, Rio de Janeiro e São Paulo, e sim em cidades que ficaram a meio passo entre o desenvolvimento e a modernização urbana sofrendo o peso do passado e do atraso rurais.

É no sexto capítulo que Luís da Silva menciona sua empregada, D. Vitória, definindo-a como uma mulher terrivelmente feia, em torno dos cinqüenta anos, meio surda e possuidora de um papagaio inteiramente mudo. $\mathrm{O}$ narrador chama a atenção para algumas de suas extravagâncias, como falar com o papagaio e ler com atenção o nome dos navios que chegam e saem do porto de Maceió, ainda que nunca tenha embarcado. Mas é a obsessão da velha por guardar suas moedas o que mais chama a atenção do narrador. 
No princípio do mês, quando se aproxima o recebimento do ordenado, excitase e não larga o Diário Oficial.

- Faltam dois dias, falta um dia, é hoje.

E faz cálculos que não acabam, cálculos inúteis, porque não gasta nada: usa os meus sapatos velhos e traz um xale preto amarelento que deve ter dez anos. Recolhe a mensalidade e mete-se no fundo do quintal, põe-se a esgravatar a terra como se plantasse qualquer coisa. Esquece os navios e as lições ao papagaio.

Volta a tratar das ocupações domésticas, mas de quando em quando lá vai rondar a mangueira e acocorar-se junto ao canteiro das alfaces. Dá um salto à cozinha, fala com o louro, tempera a bóia. Minutos depois está novamente remexendo terra. (RAMOS, 2003, p. 28)

Essa mania de guardar dinheiro, associada ao nenhum gasto que a criada tem, pode ser fruto de um pavor semelhante ao de D. Plácida de cair na mendicância, acreditando a velha que apenas suas moedas poderiam salvá-la na falta de Luís da Silva. Novamente aqui a pouca estima pelo trabalho deixa a pobre mulher à mercê dos caprichos da classe dominante, e o valor da pessoa depende do reconhecimento arbitrário de algum proprietário (SCHWARZ, 2000), ainda que no mundo degradado de Luís da Silva este proprietário não precise ser pai de família como o de Virgília ou fillho abastado como Cubas, basta um reles funcionário público, solteiro e com uma casa para cuidar.

É no capítulo vinte e cinco, entretanto, que o capricho do narrador opõe-se aos valores da empregada, como outrora os encontros fortuitos de Cubas obrigaram D. Plácida ao vil papel de alcoviteira. Luís da Silva já afastara-se de Marina, mas queria estar em seu encalço e, para tanto, era necessário ir a certo espetáculo em camarotes, para o que o homem não tinha dinheiro. Seu ordenado sairia dali a dias, mas naquele momento Luís da Silva não dispunha dos vinte mil-réis necessários nem de amigos a quem pedir. É quando lembra que "ali, perto da raiz, ao pé da cerca, no canteiro das alfaces, escondia-se a fortuna de Vitória" (RAMOS, 2003, p. 117). Luís hesita, tem consciência de estar fazendo uma ação indigna, ainda que prometa pagar a mulher com juros. Chega a pensar num jogo de cara ou coroa para decidir-se quando finalmente dáse conta do ridículo da situação e resolve seguir adiante: "um homem livre. Perfeitamente, um homem livre de superstições. Comecei a cavar a terra com desespero, ralando os dedos. Estava decidido. Pronto! Seis dias depois colocaria no buraco o duplo da quantia retirada" (ibid., p. 121).

Brás Cubas, em capítulo adiantado de suas memórias, receberá um bilhete de Virgília, com quem já não mantém relações. A moça pede que ele visite D. Plácida em certo beco e ajude-a a ir para a Misericórdia, pois a empregada está muito mal. Cubas primeiro lembra do pecúlio de cinco contos e se nega a ajudar a velha, perguntando-se o que teria feito ela com o dinheiro. Mas acaba por ceder e vai encontrar na casa de D. Plácida "um molho de ossos, envolto em molambos, estendido sobre um catre velho e nauseabundo" (ASSIS, 1997, p. 201). A mulher morrerá dias depois, na Misericórdia, e Cubas se perguntará para que, afinal, D. Plácida havia nascido, achando por fim uma utilidade, ainda que relativa: "se não fosse D. Plácida, talvez os meus amores com Virgília tivessem sido interrompido, ou imediatamente quebrados, em plena efervescência. (...) Utilidade relativa, convenho, mas que diacho há absoluto nesse mundo?" (ibid., p. 201).

Trouxemos as memórias de Brás Cubas de volta porque é esta a lógica de Luís da Silva ao pegar as moedas de D. Vitória, a da utilidade relativa de sua empregada. O 
homem resolve-se ao se definir como um "homem livre", livre de superstições, sim, mas também livre de patrões a quem o capricho dependeria a sobrevivência, enquanto D. Vitória - e D. Plácida - estão em suas posições para colaborarem com seus patrões em particular e com a classe dominante em geral, seja essa classe dominante o rico Cubas ou o decadente Silva. Assim, cabe a elas, e não ao narrador-protagonista-proprietário, o papel vil, a humilhação, a desolação, os momentos duros, a singular tristeza. Cabe a elas, em última instância, à fatia pobre da população, reproduzir a lógica que é sua desgraça:

\footnotetext{
A pobreza está descrita em seu ciclo regular, por assim dizer funcional, e não falta método a seu absurdo. Neste sentido ela tem sim uma finalidade, embora humanamente insustentável, qual seja a de reproduzir a ordem social que é a sua desgraça. (SCHWARZ, 2000, p. 16)
}

Neste ponto vale ressaltar que não estamos sendo originais em aproximar Machado de Assis e Graciliano Ramos. Historiadores da literatura já disseram que "de todos os narradores nordestinos, Graciliano Ramos é o mais clássico e o mais machadiano" (PICCHIO, 2004, p. 533). Álvaro Lins, em ensaio no ano de 1943, já chamava a atenção para as aproximações possíveis entre Machado e Graciliano, afirmando que uma mesma concepção da vida, um mesmo julgamento dos homens e uma mesma estrutura temperamental aproxima os dois: "já houve mesmo quem falasse de influência, e o Sr. Graciliano Ramos se defendeu com um argumento fulminante: que nunca havia lido antes Machado de Assis" (LINS, 1977, p. 140).

À parte a questão direta da influência, os pontos de contato entre a obra de um e outro são bastante evidentes para um olhar distanciado no tempo como o nosso. Em ambos há o que Lins chama de preocupação de fixar e exibir o caráter humano, associado a um recurso formal que dá a voz à classe dominante (tanto Memórias Póstumas quanto Angústia são narrados em primeira pessoa), permitindo que a última palavra seja da parte beneficiária da injustiça em detrimento da parte pobre, cujo ponto de vista permanecerá inexpresso (SCHWARZ, 2000, p. 110). Dessa forma, uma leitura apressada dos dois romances poderia deixar transparecer uma falta de simpatia por parte do autor em relação a sorte de suas personagens:

Esta preocupação de fixar e exibir o caráter humano poderia significar que o Sr. Graciliano Ramos estima os seus semelhantes e está interessado pela sua sorte. Mas não. Verifica-se o contrário; o seu julgamento dos homens é o mais pessimista e frio que se possa imaginar; o seu sentimento em face deles é de ódio ou desprezo. (LINS, 1977, p. 139)

Schwarz (2000, p. 110-111), entretanto, verá essa postura do narrador de Graciliano e Machado como uma espécie de delação de si mesmo, uma verdadeira traição de classe. O procedimento, segundo o crítico, choca pelo cinismo, e de fato se observarmos a influência que as figuras de D. Plácida e D. Vitória exercem sobre os narradores-protagonistas veremos que nem eles ficam alheios à compaixão exercida pelos vencidos.

Brás Cubas, muito antes da reflexão sobre a utilidade relativa da criada, no capítulo setenta e seis sente um "repelão da consciência", que acusa-o de "ter feito capitular a probidade de D. Plácida, obrigando-a a um papel torpe, depois de uma longa vida de trabalho e privações" (ASSIS, 1997, p. 133). Menciona a resistência da mulher nos primeiros dias, as lágrimas, os silêncios, os olhos baixos, demonstrando uma clara 
contrariedade com a situação da empregada, o que no nosso entender deixa transparecer uma preocupação social, se não do narrador, da obra. Note que mesmo a solução desta pequena crise de consciência de Cubas, que vem já no parágrafo seguinte - quando ele reflete que se não fossem os seus amores com Virgília provavelmente D. Plácida acabaria como tantas outras criaturas humanas, na mendicidade - é uma solução tão cínica que se enquadra na delação de classe formulada por Schwarz. Desta forma, em se tratando de uma obra literária, o narrador não tem a última palavra, e sim a penúltima, cabendo a última a um leitor que saberá entender o escárnio da postura de Cubas, o que finalmente dará à obra o tom da preocupação social.

No caso de Luís da Silva, o sentimento de culpa é ainda maior e não se resolve em nenhum parágrafo seguinte, pelo contrário, talvez seja mais um elemento que o levará a insana atitude dos últimos capítulos. Como mencionado acima, o patrão pega as moedas enterradas da empregada e de fato as devolve em dobro alguns dias depois, mas inadvertidamente coloca as moedas empilhadas, e não como lá estavam. No dia seguinte, o patrão encontra sua empregada "muito velha e muito bamba em um canto da cozinha":

Estava sentada, encolhida, movendo em silêncio os beiços moles. E quando levantava a cabeça, mostrava no rosto uma suspeita agoniada. Se ela andava com suas contas em ordem, certamente se espantava de haver achado em um dos buracos vinte e seis mil-réis a mais; se as contas não estavam em regra, talvez se julgasse roubada. E Vitória engolia em seco, olhava o Currupaco ansiosa, numa interrogação desalentada que fazia pena.

- Vá descansar, Vitória. Você está doente.

Não podia descansar, e a minha piedade era inútil. Levei o desespero a uma alma que vivia sossegada. Toda a segurança daquela vida perdeu-se. (RAMOS, 2003, p. 123)

Como Cubas, Luís da Silva sente um "repelão da consciência", dá-se conta de sua posição de classe e da submissão a que se encontra a empregada, obrigada a "engolir em seco", incapaz sequer de suspeitar do patrão ou questioná-lo. Como a honra de D. Plácida, a segurança de D. Vitória foi violada e nada mais podem fazer os proprietários-narradores-protagonistas do que terem compaixão, afinal elas são as vencidas.

Até aqui analisamos duas obras clássicas de nossa literatura, uma do final do século XIX e outra da primeira metade do século XX, faltando ainda trazer à discussão a obra contemporânea de Milton Hatoum. O escritor tem sido saudado como o grande romancista contemporâneo e comparado inclusive a Graciliano Ramos por "unir o social ao existencial" (PIZA, 2004, p. 17), influência que Hatoum não nega quando questionado sobre suas fontes: "Graciliano Ramos e Machado de Assis foram autores importantes" (HATOUM, 2004b, p. 100). O amazonense Milton Hatoum é autor de Relato de um certo oriente, publicado em 1989, Dois Irmãos, de 2000, e Cinzas do Norte, de 2005, todos vencedores do Prêmio Jabuti. Em Dois Irmãos, publicado na virada do século XX para o XXI, é que aparece Domingas, uma espécie de neta da sina de D. Plácida.

Contemporaneamente, pós abolição e república, grandes guerras, revoluções de direita e de esquerda, ascensão e queda das utopias capitalista e comunista, esta "sina" pode ser traduzida como pertencer a uma "subclasse, um grupo heterogêneo de pessoas que tiveram o seu bios (ou seja, a vida de um sujeito socialmente reconhecido) reduzido a zoe (a vida puramente animal), com todas as ramificações reconhecidamente humanas 
podadas ou anuladas" (BAUMAN, 2005, p. 46). A essa subclasse pertencem desempregados urbanos, sem terra rurais, operários braçais, motoqueiros alucinados ou prostitutas baratas, mas, como nenhuma outra categoria, as empregadas domésticas especialmente aquelas que cresceram na casa dos patrões e dormem no serviço. Estas seguem, cem anos depois, espremidas entre os ônus da liberdade e os da escravidão, como na formulação schwarziana para o tempo do Rei. Domingas, por exemplo, é descrita em dado momento de Dois Irmãos como "meio escrava, meio ama, louca para se ver livre, (...) cansada, derrotada, entregue ao feitiço da família, não muito diferente das outras empregadas da vizinhança" (HATOUM, 2000, p. 67).

$\mathrm{O}$ romance de Milton Hatoum se passa na cidade de Manaus em processo de urbanização, com o fim da história culminando nos anos da ditadura militar, o que nos indica que os episódios ocorram em meados do século XX. O conflito que dá título ao livro e permeia toda narrativa é o de dois irmãos gêmeos que crescem se odiando, em meio a brigas e grande rivalidade, conflito este que serve de pano de fundo para explorar a degradação dos valores familiares na modernidade. Quem narra a história é Nael, filho da empregada da casa, que aos poucos sabemos ser filho de um dos dois gêmeos - e a narrativa se mostra também a busca de Nael pela sua identidade.

Esta empregada, como D. Plácida e D. Vitória, trabalha e mora na casa dos patrões, não conhece outro mundo senão aquele a que serve e está sujeita ao capricho imediato dos seus patrões - especialmente a mãe da família, Zana, e o filho caçula, Omar. Diferentemente de D. Plácida e D. Vitória, Domingas chegou para a família de Zana e Halim ainda pequena e cresceu nos fundos da casa, onde havia dois quartos separados por árvores e palmeiras. Mais do que uma coadjuvante na narrativa, Domingas - definida como "uma beleza de cuinhatã" - é uma personagem central para o enredo porque liga o narrador, Nael, aos protagonistas, os gêmeos, importância esta que não escapou ao autor no momento de composição da obra, como expressa em artigo sobre a construção antropológica de Domingas.

\footnotetext{
Concebido para ser um personagem de relevo na narrativa, tentei dar espessura ao que ela faz, e ao que sente e pensa em relação aos outros. (...) Um dos traços que acentuei foi o trabalho e o cotidiano do personagem: ela é uma mulher que não descansa nem aos domingos; às vezes é humilhada por um dos irmãos ou pela mãe deles, a patroa. (HATOUM, 2004b, p. 139)
}

Neste artigo o autor também conta que compôs a personagem a partir de outras empregadas domésticas da literatura mundial (especialmente Félicité) e brasileira, citando nominalmente D. Plácida (ibid., p. 140). Há na personagem de Hatoum, entretanto, uma diferença fundamental em relação às duas empregadas anteriormente por nós abordadas, uma diferença que problematiza ainda mais a existência e a pobreza da personagem e potencializa a problemática social na narrativa: o narrador não é mais o protagonista, o proprietário, e sim o filho desta empregada doméstica. Mais do que isso, ele é filho de um dos dois gêmeos - não se saberá ao certo qual - e essa condição ao mesmo tempo que lhe permite ser um agregado arraigado à casa, impede que estude, trabalhe e viaje como os autênticos filhos dos senhores, Yaqub e Omar. Não se sentindo parte da família, em diversos momentos o narrador expressa claramente o desejo de partir, fugir, deixar aquela casa que lhe oprime e humilha - mas não o faz por causa da mãe, para protegê-la dos caprichos de seus patrões ou pelo menos amenizar sua sorte.

[Quando eu pensava em fugir] a imagem da minha mãe crescia na minha cabeça, eu não queria deixá-la sozinha nos fundos do quintal, não ia 
conseguir... Ela nunca quis se aventurar. "Estás louco? Só de pensar me dá uma tremedeira, tens que ter paciência com a Zana, com o Omar, o Halim gosta de ti." Domingas caiu no conto da paciência, ela que chorava quando me via correndo e bufando, faltando aula, engolindo desaforos. (HATOUM, 2000, p. 90)

Esta mudança social de narrador, que poderia dar uma sensação de libertação para a obra, mostra-se ao longo da narrativa incapaz de solucionar a problemática já suscitada em Memórias Póstumas ou Angústia, tendo o mesmo efeito devastador das narrativas em primeira pessoa de Machado e Graciliano. Aos poucos o leitor vai percebendo o quanto também Nael está à mercê dos caprichos dos patrões, da classe dominante, desde a sua concepção. Singular neste aspecto é o momento em que Nael insiste mais uma vez com a mãe para que ela diga qual dos gêmeos é seu pai. É então que se revela a violação definitiva de Domingas, sua maior redução de bios a zoe, violação mais explícita e grave que a da honra de D. Plácida, transformada em vil alcoviteira, ou a da segurança de D. Vitória, roubada pelo patrão.

\footnotetext{
Ela [Domingas] me enlaçou, beijou meu rosto e abaixou a cabeça. Murmurou que gostava tanto de Yaqub... Desde o tempo em que brincavam, passeavam. Omar ficava enciumado quando via os dois juntos, no quarto, logo que o irmão voltou do Líbano. "Com o Omar, eu não queria... Uma noite ele entrou no meu quarto, fazendo aquela algazarra, bêbado, abrutalhado... Ele me agarrou com força de homem. Nunca me pediu perdão. Ela soluçava, não podia falar mais nada. (ibid., p. 201)
}

Vencida, resta à Domingas despertar em seu filho ódio e compaixão, ódio daquele que a violou - e o gerou - e compaixão pela sua ignorância sobre a paternidade. A Nael, também vencido, resta transformar esse ódio e essa compaixão em uma narrativa feita de memórias, tentando resgatar com o ato de narrar a dignidade jamais alcançada pela mãe e negada também a ele. Por isso sua narrativa não tem o cinismo de um Brás Cubas nem a angústia de um Luís da Silva, sua narrativa expõe de frente a preocupação social a partir da pobreza de sua mãe em frases como "Domingas serviu; e só não serviu mais porque a vi morrer, quase tão mirrada como no dia em que chegou à casa, e, quem sabe, ao mundo" (ibid., p. 65).

Afora este estreitamento entre narrador e personagem, a função social e narrativa de Domingas guarda profundas semelhanças com as de D. Plácida e D. Vitória nos romances de Machado de Assis e Graciliano Ramos, ainda que as três obras sejam bastante diferentes em sua trama, espaço e data de publicação. Mais do que a presença recorrente desta personagem pobre, trabalhadora, sofrida mas honrada e finalmente violada, é interessante notarmos o quanto nas três obras aqui analisadas sua existência afeta o narrador e interfere no narrado, culminando num romance que só existe por causa desse conflito.

Dessa forma, parece possível apontarmos, primeiro, para o fato de que a problemática social no Brasil é antiga e não resolvida e, segundo, para o fato de que essa problemática é preocupação de nossos escritores, de nossa literatura, mesmo quando não é assunto de fundo das obras (como o é, por exemplo, em O Cortiço (1881), de Aluízio Azevedo, obra publicada no mesmo ano de Brás Cubas; em Vidas Secas (1938), do mesmo Graciliano Ramos; e em Subúrbio (1994), de Fernando Bonasi, contemporâneo de Hatoum). A este respeito, Schwarz já afirmava que "basta não confundir poesia e obra de ciência, e não ser pedante, para dar-se conta do óbvio: que 
poetas sabem muito sobre muita coisa, inclusive, por exemplo, sobre a pobreza" (SCHWARZ, 1983, p. 7). Afirmação que nos permite entender as empregadas domésticas de Machado, Graciliano e Hatoum como representações de toda uma classe social, uma classe que poderíamos dizer a dos vencidos, a dos que serviram toda uma vida para reproduzir a ordem que os exclui. A estes, resta apenas ódio ou compaixão. Enquanto ao vencedor, as batatas.

\section{REFERÊNCIAS}

ASSIS, Machado de. Memórias Póstumas de Brás Cubas. São Paulo: Objetivo, 1997.

BAUMAN, Zygmunt. Identidade. Rio de Janeiro: Jorge Zahar Editora, 2005.

GIL, Fernando Cerisara. O romance da urbanização. Porto Alegre: EDIPUCRS, 1999.

HATOUM, Milton. Dois Irmãos. São Paulo: Companhia das Letras, 2000.

. Laços de parentesco: ficção e antropologia. In: PEIXOTO, Fernanda Áreas; PONTES, Heloísa; SCHWARCZ, Lília Moritz (orgs.). Antropologia, história, experiências. Belo Horizonte: UFMG, 2004. p. 135-141.

. Entrevista. Revista de Literatura Brasileira Brasil/Brazil - Revista do Instituto

de Letras da PUCRS, Porto Alegre, n. 31, p. 93-103, 2004B.

LINS, Álvaro. Valores e misérias das Vidas Secas. In: RAMOS, Graciliano. Vidas Secas. Rio de Janeiro: Record, 1977. p. 135-167.

PIZA, Daniel. Destinos danados. Revista Entre Livros, São Paulo, n. 5, p. 16-19, setembro de 2005.

RAMOS, Graciliano. Angústia. Rio de Janeiro: O Globo; São Paulo: Folha de S. Paulo, 2003.

SCHWARZ, Roberto. Ao vencedor as batatas. São Paulo: Duas Cidades, 1977. (org.). Os pobres na literatura brasileira. São Paulo: Brasiliense, 1983.

Um mestre na periferia do capitalismo. $3^{\mathrm{a}}$ ed. São Paulo: Duas Cidades, 2000.

STEGAGNO-PICCHIO, Luciana. História da Literatura Brasileira. $2^{\mathrm{a}}$ ed. Rio de Janeiro: Nova Aguilar, 2004. 